\title{
The Research on the Optimization Path of the Security Council's Authority to Deal with the Global Climate Crisis
}

\author{
Shengyu Fei ${ }^{1, *,+,}$, Yuxuan Guo ${ }^{2, \dagger}$, Hangzhi $\mathrm{Lu}^{3, \dagger}$, Touyuan $\mathrm{Xu}^{4, \dagger}$ \\ ${ }^{1}$ Villanova Preparatory School, Ojai, California, United States \\ ${ }^{2}$ Insight Academy of Canada, Taiyuan, Shanxi, China \\ ${ }^{3}$ WLSA Shanghai Academy, Shanghai, Shanghai, China \\ ${ }^{4}$ Shanghai United International School Gubei Campus, Shanghai, Shanghai, China \\ * Corresponding author. Email: ${ }^{1}$ sfei@cpp.edu \\ ${ }^{t}$ These authors contributed equally.
}

\begin{abstract}
The global climate crisis has become the focus of attention in international community. The massive emissions of six greenhouse gases and various natural disasters have made the climate problem intensified. The UN Security Council has made some efforts to manage the global climate problem. These efforts are reflected in the following: to begin with, it has called for international conferences to discuss how to deal with the global climate problem. Besides, it has also established different organizations to help countries manage the climate problem. In order to propose an effective solution to the climate issue from a legal perspective, this paper demonstrates the powers of the Security Council, clarifies how the Security Council can help countries deal with climate issues, and discovers that it still has insufficient powers. Based on this, the main current efforts are three ways to optimize the powers of the Security Council, with a view to solving the problem of global climate governance.
\end{abstract}

Keywords: The UN Security Council, Global climate crisis, Authority, Optimal path.

\section{INTRODUCTION}

Climate change is a huge challenge for all mankind to cope with. Just as scholars say, for decades, people has continued to emit GHGs at these high rates, despite convincing evidence that people were thereby contributing to the risk of dangerous climate change. This, of course, affected everyone on the planet. A warming climate was bad for Australians; it was bad for those in other countries, and often worst for the poorest people in the world [1]. With the rapid development of the world economy and the rapid improvement of people's living standards, environmental pollution has also reached unprecedented heights. The United Nations, as yet, had convened 5 meetings to work on global climate governance, discussing the convention and subsequent supplementary provisions. Climate change will directly affect the daily life of human beings. Even though most of the reasons are due to excessive emissions of greenhouse gases, it is undeniable that the impact of human activities is also great.

This paper mainly discusses and studies China's increasingly severe environmental and climate problems and the UN's solutions to this problem. This article will further explore the UN's main measures and methods for China's environmental and climate issues by discussing the UN Security Council's existing rule of law efforts, China's current climate issues and the scope of the UN's powers, as well as the UN's optimization of its powers in response to China's climate issues. This is to better solve such problems and further confirm the responsibilities and rights of the United Nations.

\section{UN'S EXISTING RULE OF LAW EFFORTS}

The climate issue is the top priority of the international community, and climate change will change the living environment of mankind. Climate 
change is one of the most pressing social justice issues of our time-not only because of the magnitude of the harm it inflicts, but also because of its disproportionate impact on those who have contributed least to the problem [2]. Therefore, this requires that the UN Security Council should play its role to organize countries to discuss how to solve global climate governance issues.

\subsection{Holding conferences and setting up specialized organizations}

The United Nations had convened several meetings in history to commit itself to global climate governance. In response to this situation, the UN Security Council held the first meeting to solve global climate problems: In June 1972, the first UN Conference on the Human Environment was held in Stockholm, Sweden. The content is: passed the "Human Environment Declaration" and the important report "Only One Earth" written by more than 100 scientists, and put forward the slogan "Protecting and improving the environment for this and future generations."

Then in 1992, the United Nations Security Council convened in Rio de Janeiro, Brazil and passed the "United Nations Framework Convention on Climate Change." What I want to emphasize next is: This convention was the first international convention in the world to completely control carbon dioxide and various greenhouse gas emissions, and to deal with global warming and the adverse effects of various changes on the human environment, and was also an international cooperation made by the international community in the face of climate issues.

The "Convention" entered into force in March 1994. This convention was a model for the international community to deal with climate issues. Under the call of the United Nations, the international community organized the third social conference to supplement the convention.

In December 1997, in Kyoto, Japan, the international community organized the third conference to supplement the convention under the call of the United Nations. The purpose of this supplementary convention was: in order for all mankind to avoid the threat of global warming, developed countries must reduce greenhouse gas emissions. On February 16, 2005, the "Kyoto Protocol?officially entered into force. Its significance was that it was the first time in human history that an initiative to limit greenhouse gas emissions had been established in the form of a convention. Moreover, the discussion in 2007 at the UNSC on climate change was not an isolated event. It was followed by a meeting in 2011, two in 2015 and a further one in April 2017. These meetings had followed the Arria formula, meant to encourage more informal discussions that did not necessarily lead to the adoption of formal documents, hence giving countries more space to voice their positions and concerns [3].

The United Nations had established a specific functional organization to help people of all countries deal with environmental problems. That was because Institutionalization, one of the manifestations of international cooperation, could be achieved through a variety of means, including the establishment of an institution by cooperating parties [4].

In order to advocate and stimulate human awareness of environmental protection, since 2004, the United Nations Environment Agency had been cooperating with the Iraqi government to restore what many people regard as the "Garden of Eden" in the biblical story. The ecological environment of the Mesopotamian swamps, and citizens of Antigua and Barbuda would face the harm of being corroded by plastic bags when they used plastic bags. The country used nearly tens of millions of plastic bags every year, many of which were eventually abandoned on the beaches and oceans. In early 2016, the government announced a total ban on plastic bags. The United Nations Environment Program provided feedback and technical support. Since 2005, the United Nations Environment Program had been supporting Penang's greening work, and through some efforts, it had helped Penang to establish countermeasures to solve pollution and helped the city achieve its development goal of becoming a green city.

\subsection{Establishment of climate control mechanism and facilities}

Moreover, the United Nations had also helped countries formulate their own climate framework documents and corresponding climate governance mechanisms. In the "United Nations Framework Convention on Climate Change", the United Nations had put forward some requirements on developed countries, and clearly stated that developed countries should undertake the obligation to take the lead in reducing emissions and provide financial and technical support to developing countries, so as to help developing countries cope with various issues including similar climate change issues. Secondly, it was recognized that developing countries had priority needs for poverty eradication and economic development. The "Kyoto Protocol? stipulated that by 2010 , the emissions of six greenhouse gases including carbon dioxide in all developed countries would be reduced by $5.2 \%$ compared to 1990. In other words, the reduction targeted that the developed countries must complete these from 2008 to 2012 Compared with 1990, the EU cut $8 \%$, the United States cut $7 \%$, Japan cut $6 \%$, Canada cut $6 \%$, and Eastern European countries cut $5 \%$ to $8 \%$. New Zealand, Russia and Ukraine could stabilize emissions at 1990 levels. The protocol also allowed 
Ireland, Australia and Norway to increase emissions by $10 \%, 8 \%$ and $1 \%$ respectively over 1990 .

The United Nations had helped countries build some public facilities for climate governance. It had installed solar energy equipment for India, enabling nearly 100,000 people in India to have solar energy equipment systems and improving the living environment of local residents. Because this initiative had been implemented successfully in India, the United Nations had implemented similar projects in Tunisia, Morocco, Indonesia, and Mexico.

\section{NORMATIVE ANALYSIS OF THE POWERS AND RESPONSIBILITIES OF THE UN SECURITY COUNCIL}

The United Nations is a product of international law. It exists in accordance with the "United Nations Charter"and is an international organization. The United Nations Charter, as an agreement between states, is a multilateral agreement that is binding on all signatories. The United Nations Security Council (referred to as the Security Council) is the most powerful body in the United Nations, responsible for maintaining international peace and security. According to the "UN Charter", the Security Council is different from other UN agencies in that the decisions it makes must be obeyed and implemented by the relevant member states. The decisions made by the Security Council are called UN Security Council resolutions. In addition, the Security Council must maintain international peace and security in accordance with the purposes and principles of the United Nations, take a series of measures to protect world peace, mediate conflicts among countries, and formulate some plans to deal with and respond to threats or acts of aggression and take military actions against invaders, which is specifically manifested as:

Firstly, the Security Council can resolve disputes to maintain peace in the international community (Article 33). When two countries encounter some difficult to resolve conflicts, the Security Council can come forward to mediate. For example, the United Nations will send a peacekeeping force composed of 6,240 military personnel and 350 civilian police to Côte $\mathrm{d}$ 'Ivoire, and the peacekeeping force will also include an appropriate number of civilian personnel. This peacekeeping force will be deployed in Côte d' Ivoire on April 4 this year, with a preliminary term of 12 months.

Secondly, it calls on all countries to take any temporary measures to prevent the situation from deteriorating (Article 40), such as reducing greenhouse gas emissions, and calls on all countries to formulate conventions. In order to reduce carbon dioxide and other greenhouse gas emissions, the United Nations Security
Council convened a meeting with all countries to discuss together Solve this problem.

Thirdly, the Security Council can urge the international community to work together to solve economic development and education issues (Article 55). For example, international organizations such as the United Nations and the World Bank had recently issued multiple reports to focus on the education problems of children, especially girls, in poor countries and regions. The phenomenon of equality called on all countries to take effective measures to pay more attention to the fair distribution of educational resources. The United Nations report entitled "World Social Report 2020: Inequality in a Changing World"pointed out that due to the uneven distribution of funds, children living in urban high-income families benefited more from government education expenditures than children from low-income rural families. The continuous expansion of the disparities in the distribution of educational resources will lead to increased wage and income inequality. This fully illustrates the series of policy changes the Security Council has made on some unequal education issues.

Finally, the United Nations can call on all countries to participate in conferences and discuss how to deal with various problems and crises in a series of conferences, and sign at these conferences, demonstrating their belief in jointly complying with and implementing the resolutions. Some refugees cannot guarantee their personal safety in the epidemic environment. UNHCR had called on the international community to unite and take coordinated actions to ensure that refugees and other forcibly displaced and stateless people have fair access to the new crown vaccination. The Security Council had adopted a region and a region to distribute vaccines. Therefore, most refugee gathering places around the world now had vaccines, ensuring the most basic personal safety of refugees. From this it could be seen that the scope of the Security Council's work is broad and specific. It includes sustainable development, protection of the environment and refugees, relief of victims, combating terrorism, promotion of disarmament, promotion of democracy, protection of human rights, and promotion of economic and social development. The most important purpose is giving present and future generations a safer world.

Observing the practice of Global Climate Governance of the United Nations, it could be found that the UN Security Council has insufficient legislative power and sanctions power, so that the relevant effective climate control measures are difficult to carry out and achieve good results. 


\section{THE PATH TO OPTIMIZE THE MANDATE OF THE UNITED NATIONS IN TACKLING CLIMATE ISSUES}

Climate change is a global concern of humankind. The impacts will touch almost every aspect of people's lives and countering the challenge requires a comprehensive international response [5]. First of all, it is necessary to note that the principle of climate justice has an important relationship with the UN Security Council's global climate governance. As climate change progresses and the global economy shifts, so should the principles of climate justice-including CBDRRC, the right to development, and public participation-evolve, as well. The UNFCCC, as the preeminent forum for climate change diplomacy, has also had to come to grips with the changing political and economic landscape over the past two decades [6]. Obviously, attention should be paid to the UNFCCC. What needed paying attention to here is that The UNFCCC"s premise is that climate change is a serious problem, human activities are primarily responsible and, by working together, states can provide a solution [7].

Secondly, while most prefer to see the matter dealt with in the (relatively) democratic and egalitarian framework of the UNFCCC, the possibility must be considered that that process alone may not be sufficient to deal with the complex and multifarious challenges presented by international climate regulation [8]. The United Nations should be able to make suggestions to countries regarding the climate change crises when the countries themselves agree to it, using the science data supplied by the organizations mentioned previously. Condemnations should be made when the UN sets a specific legally binding policy meant for all countries to obey, and that policy is broken by a specific country. Meanwhile, The UNSC could pick up the recent IPCC Report and transplant some of its core findings into a resolution. This would give the IPCC findings a forum in which to have greater impact and would provide the UNSC a sound platform from which to draw from in the creation of its non-binding but precise directives [9]. Policies and treaties instated by the UN should involve listening to the opinions of both the G-77 and Umbrella Group to ensure balance, and should attempt to reduce the amount of carbon emissions into the atmosphere as an attempt to solve the greenhouse gas problem.

In addition, it may hope that the United Nations can issue some resolutions containing universal principles, which put forward general principles on special climate issues, such as climate refugees, so that countries could introduce them into domestic laws as principles of international law. It has to be mentioned that starting from the argument that climate, change and climate change induced displacement are permanent phenomena and the recognition that many of today's refugees are also climate-refugees, an amendment or a new legal framework is already needed to reflect the reality and afford legal recognition to this new emerging type of refugees [10]. This may be a matter that needs to be established by the UN Security Council.

Lastly, economic and diplomatic sanctions should be imposed when a country violates international law by threatening international peace and security, meaning they prove a threat to the goal that the United Nations Security Council is trying to accomplish. Smaller sanctions such as tariffs could be imposed by the country itself, while larger more impactful sanctions like embargoes should be approved by the United Nations first before being launched and enforced. What can be included in economic and diplomatic sanctions needs to be decided by the UN Security Council. The possible solution is for the UN to formulate a specific operational catalogue to promote the effective implementation of sanctions.

\section{CONCLUSION}

Climate problem is a huge global problem. The United Nations must strengthen the construction of laws and regulations, and call on all countries to abide by these treaties. In other words, there is necessity to build a complete legal system to make the UN Security Council have a greater discourse power.

This paper mainly explains: the UN Security Council governs climate issues by holding meetings, signing conventions and establishing organizations. However, the Security Council has not completely dealt with the climate issue well. It cannot use its own authority to let all countries cooperate with it. The convention has no obvious effect. The annual emissions have not decreased significantly. This is because each country has not fully cooperated with the solution of the climate problem. The Security Council has a great responsibility: firstly, to resolve disputes among countries and to maintain global security issues. Secondly, call on all countries to take any temporary measures to prevent the situation from deteriorating. Finally, the Security Council can urge the international community to work together to solve the problems of economic development and education.

In order to solve the problem that the legislative power and sanction power of the Security Council are insufficient, the UN should optimize its functions and powers in dealing with climate issues through the following ways: first of all, the UN should solve the problem through the formulation of conventions; Secondly, diplomatic, economic and military sanctions should be implemented to against some unreasonable acts. However, it is expected that the optimization of the two paths will have important reference value for solving this climate problem. At the same time, it should be made clear that this paper only studies global climate 
issues from the perspective of the Security Council's functions and powers, and does not involve other issues.

\section{REFERENCES}

[1] Moss, J., \& Kath, R. (2018). Justice and climate transitions. University of Tasmania Law Review, 37(2), 70-94.

[2] Gonzalez, C. G. (2019). Climate justice and climate displacement: Evaluating the emerging legal and policy responses. Wisconsin International Law Journal, 36(2),366-396.

[3] Sindico, F. (2017). Climate change and security. Carbon \& Climate Law Review (CCLR),2017(3), 187-190.

[4] Menkes, J., \& Menkes, M. (2009). International Organizations, Climate Change Expectations, and the Reality of Institutionalization An Analysis of the United Nations Framework Convention on Climate Change (UNFCCC). Polish Yearbook of International Law, 29, 115-138.

[5] Elborough, L. (2017). International Climate Change Litigation: Limitations and Possibilities for International Adjudication and Arbitration in Addressing the Challenge of Climate Change. New Zealand Journal of Environmental Law, 21, 89132.

[6] Huang, J. (2017). Climate justice: Climate justice and the paris agreement. Journal of Animal \& Environmental Law, 9(1), 23-59.

[7] Beck, S., \& Burleson, E. (2014). Inside the system, outside the box: Palua's pursuit of climate justice and security at the united nations. Transnational Environmental Law, 3(1), 17-30.

[8] Conway, D. (2010). The United Nations Security Council and Climate Change: Challengesand Opportunities. Climate Law, 1, 375-407.

[9] Murphy, A. (2019). The united nations security council and climate change: Mapping pragmatic pathway to intervention. Carbon \& Climate Law Review (CCLR), 2019(1),50-62.

[10] Mastor, R. A., Dworkin, M. H., Landa, M. L., \& Duff, E. (2020). Energy justice and climaterefugees. Energy Law Journal, 41(2), 337-372. 